\title{
Rock fall trajectory field testing, model simulations and considerations for steep slope design in hard rock
}

\author{
N Bar Gecko Geotechnics Pty Ltd, Australia \\ S Nicoll Newcrest Mining Limited, Australia \\ F Pothitos Newcrest Mining Limited, Australia
}

\begin{abstract}
Newcrest Mining Limited open pit operations at Telfer (Western Australia) have excavated steep slopes. Current and future planned mine designs also intend to implement steep slopes in order to maintain profitable ore to waste strip ratios. When not adequately considered in the design process, rock falls can present a significant hazard in open pit mines. The management of rock fall hazards becomes particularly vital for steep slopes.
\end{abstract}

Numerical models are often used to assess the effectiveness of benched slope designs or rock fall barriers to minimise risk to personnel or equipment. Commonly used numerical modelling software and simulation impact theories include:

- 'RocFall' - two-dimensional lumped-mass impact model (2DLM).

- 'Trajec3D' - three-dimensional rigid body impact model (3DRB).

Numerical models use coefficients of restitution to characterise the amount of energy lost due to the inelastic deformation during the collision of a rock with the slope or bench. The input parameters are vastly different for 2DLM and 3DRB and they are seldom calibrated with any site-specific rock fall case studies or field test data during project feasibility studies, and often remain uncalibrated through the operating life of the mine.

In order to best manage rock fall hazards for steep slopes through design, a series of rock fall trajectory field tests were carried out to facilitate the development of calibrated 2DLM and 3DRB numerical models. The calibrated models were then utilised to assess the effectiveness of various slope design geometries. The influence of model selection was found to have a significant impact upon the results. This paper compares rock fall trajectory predictions obtained from calibrated 2DLM and 3DRB models for steep slope designs in hard rock.

\section{Introduction}

Rock fall is the movement of rock from a slope that is so steep that the rock continues to move down the slope. The movement may be free falling, bouncing, rolling or sliding as illustrated in Figure 1 . When inadequately managed, rock falls can present a major hazard in open pit mines. The term 'rock fall' is often widely used to describe various types of falls of ground such as individual or multiple rock falls, bench failures, landslides, or other forms of slope failure (e.g. planar, wedge, toppling, circular etc.). In the context of this paper, the term 'rock fall' is used to depict the movement of a single or multiple rocks or boulders moving down a slope.

In open pit mines, rock falls can be symptomatic of poor design implementation (e.g. poor blasting and/or scaling practices), or the result of slope degradation from weathering or freeze-thaw action. Mechanical, environmental and biological events such as earthquakes, blast vibrations, pore pressure changes due to rainfall infiltration, erosion of surrounding material during heavy rain storms, root-growth or leverage by roots moving in high winds can also initiate rock falls (Hoek 2007). 


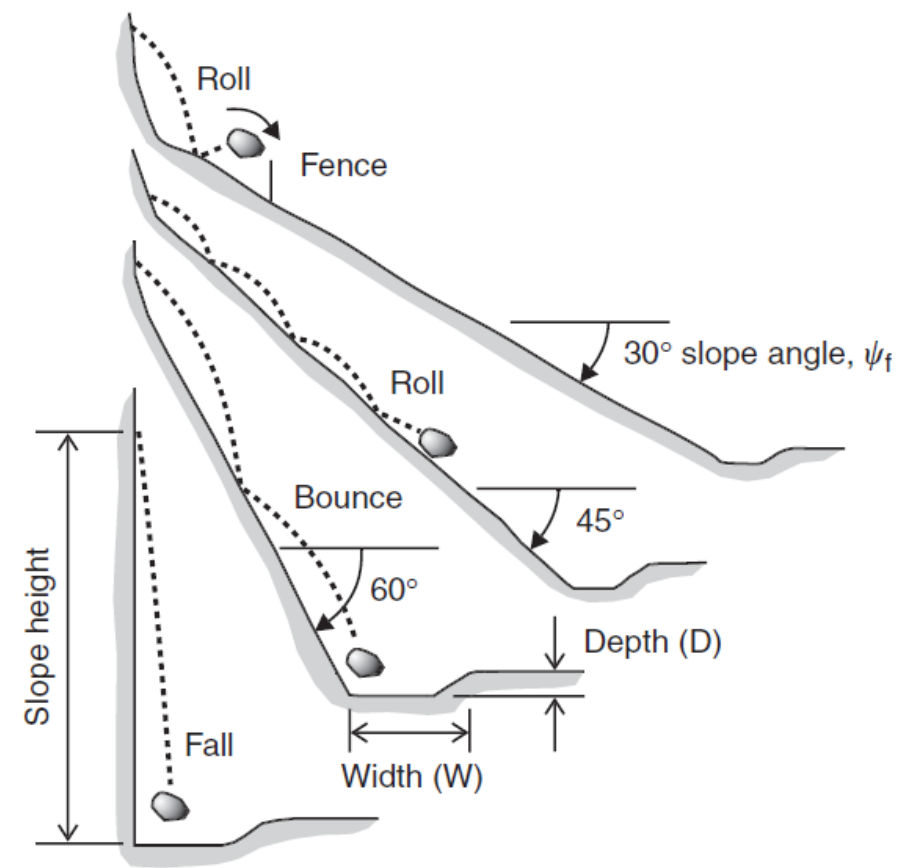

Figure 1 Rock fall modes of travel (adapted from Ritchie 1963)

Early rock fall studies in the 1960 s lead to the development of empirical ditch design charts for roadways in mountainous terrain in the United States of America (Ritchie 1963). These studies comprised hundreds of rock fall trajectory field tests to ascertain ditch dimensions. Rock fall trajectory field tests remained popular until the late 1990s, when computing power facilitated the use of numerical models to simulate rock falls using simplified impact theories.

The first such impact theory was the lumped-mass (stereomechanical) impact model in two-dimensions (2DLM). It attempted to replicate rebounding velocities of colliding objects (or an object with a stationary surface in the case of rock falls). Improvements in computational power enabled lumped-mass models to be used for probabilistic rock fall modelling. User-friendly software such as 'RocFall' of Rocscience Canada enabled most engineers to use the 2DLM impact theory.

During the 1990s several 2DLM model calibration studies were undertaken (Budetta \& Santo 1994; Chau et al. 1996; Robotham et al. 1995) utilising rock fall trajectory field tests. Model calibration became less and less 'popular' in the 2000s and appears to be almost non-existent in the 2010s.

Further improvements in computing in recent years (2010s) enabled the development of software using a slightly more complex impact theory (Ashayer 2007; Basson 2012; Basson et al. 2013) - the rigid body impact model, in both two and three dimensions. User-friendly software 'Trajec3D' of BasRock Australia can be used for three-dimensional rigid body (3DRB) impact model simulations.

In recent years, several rock fall publications have considered potential trajectories on slope designs using both 2DLM and 3DRB (Bosman \& Kotze 2015; Dadashzadeh et al. 2014). However, few, if any of these have calibrated their models with field testing.

\section{Rock fall trajectory field tests}

Rock fall trajectory field tests were carried out with the objective of calibrating numerical models to provide more realistic simulations of rock fall trajectories than merely using input parameters obtained from literature.

Rock fall trajectory field testing can (in most cases) be perceived as a hazardous task if risks are not adequately managed. A risk assessment was carried out to ensure no personnel or equipment were operating below the test areas and to ensure general awareness of the project was made around the mine. 
Several considerations for data collection were made prior to testing and included:

- Measuring rock dimensions and photographing before each test and recording observations including shape and mass estimates.

- Video recording each of the individual rock fall field tests using a slow motion video camera. Photographing after each test for estimating amount of fragmentation (if any).

- Measuring run-out distances using a tape measure or laser distance measurement device.

- Describing slope, bench and barrier (if any) characteristics including:

- Slope face conditions (smoothness, rock type, strength etc.).

- Bench floor condition (smoothness, hardness, material type etc.).

- Barriers (bunds, ditches etc.).

- Estimating slope angle variability using a clinometer and topographic survey.

Rock fall field tests were carried out using the following methods:

- Rock throw or push for rocks between 20 and $40 \mathrm{~kg}$. This induced an initial starting velocity of up to approximately $2 \mathrm{~m} / \mathrm{s}$.

- Rock levering using scaling bar to mobilise rocks between 60 and $300 \mathrm{~kg}$ from bench crests. This induced an initial rotational velocity estimated to be in the order of $90^{\circ}$ per second from video footage.

- Equipment-assisted rock drops using a telescoping handler to lift and drop rocks between 1,000 and 6,500 kg over a bench face as shown in Figure 2.

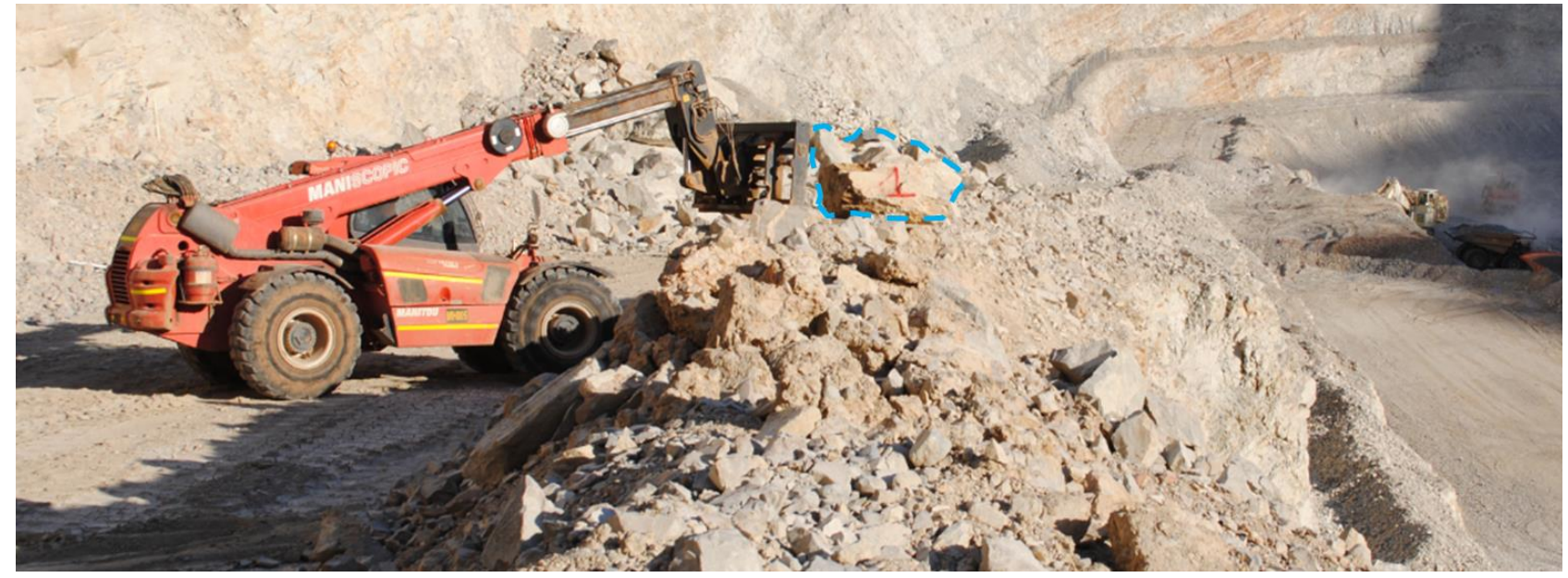

Figure 2 Telescoping handler commencing rock fall test

Initially, a total of 25 individual rock fall trajectory tests were carried out on bench face angles of $50,60,70$ and $80^{\circ}$ with multiple benches available below for travel paths. Symbolic rock shape names attributed to the rocks included square, triangle, rhombus, pentagon and hexagon (depending on the number of 'obvious' faces).

Limitations of the initial project included a relatively low number of test samples and sample size biased to smaller rocks due to equipment availability. 


\section{$3 \quad$ Model calibrations}

Rock fall trajectories from the field testing were simulated using two and three dimensional rock fall impact models. In both 2DLM and 3DRB models, observed rock fall trajectory paths were modelled in the software by adjusting relevant input parameters, in particularly, the coefficients of restitution.

\subsection{D lumped-mass impact model}

Lumped-mass or stereomechanical models consider a falling rock as an infinitesimal particle with a mass. That is, a falling body is represented as a point mass, ignoring the fall object size and shape which would otherwise affect its trajectory. The fall body mass does not affect the overall body trajectory, but is only used to compute energies. Lumped-mass impact models can only represent sliding motion and mimic rotation with a zero friction angle (Basson 2012).

Normal and tangential coefficients of restitution $\left(R_{n}\right.$ and $R_{t}$, respectively) in lumped-mass impact models are used to compensate for the lack of physics captured within the simplified models. The two parameters can depend on the characteristics of the fall body, the slope and the collision point on a fall body shape with a non-spherical shape. The normal coefficient of restitution, $R_{n}$, is described as a measure of the degree of energy dissipation in the collision of a falling body in a direction normal to the slope. The tangential coefficient of restitution, $\mathrm{R}_{\mathrm{t}}$, is the measure of the resistance to movement parallel to the slope.

Coefficients of restitution were determined from back calculation of known rock paths and endpoints from the rock fall trajectory field tests. As was expected, harder materials such as bench faces attained higher coefficients of restitution than softer materials such as bench floors as is illustrated by Figures 3 and 4 .
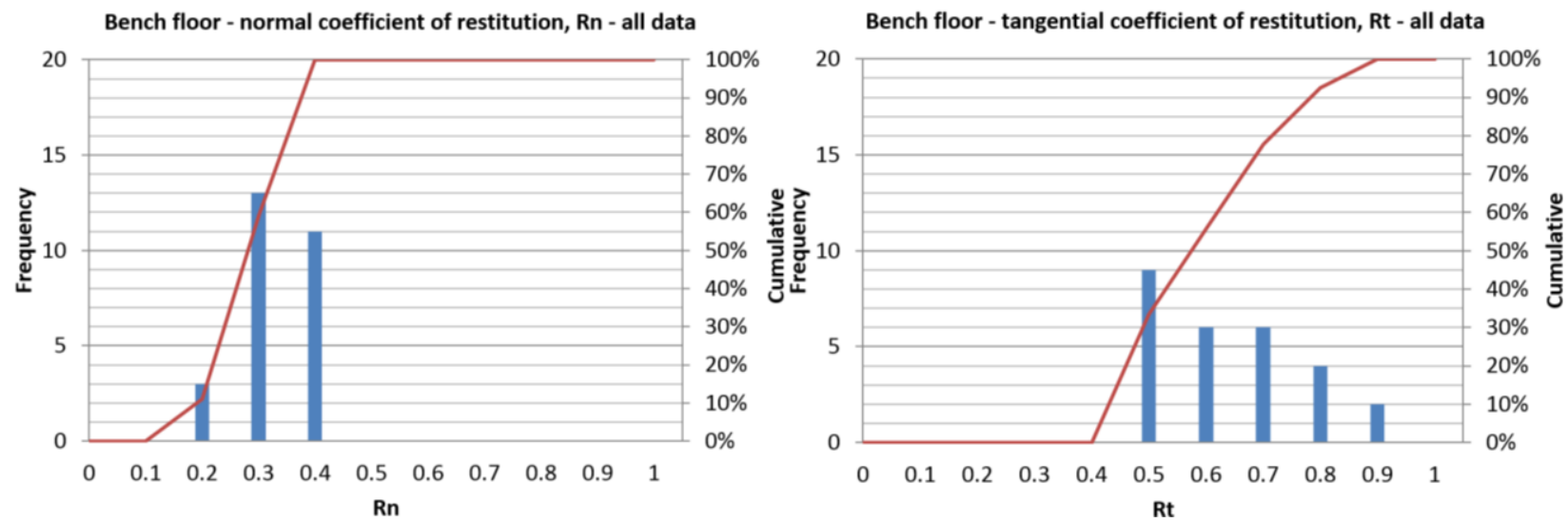

Figure 3 Histograms for bench floor coefficients of restitution from all field test data, bench floors comprised siltstone, sandstone and quartzite blasted ground and rock fill (left: $R_{n}$; right: $R_{t}$ )
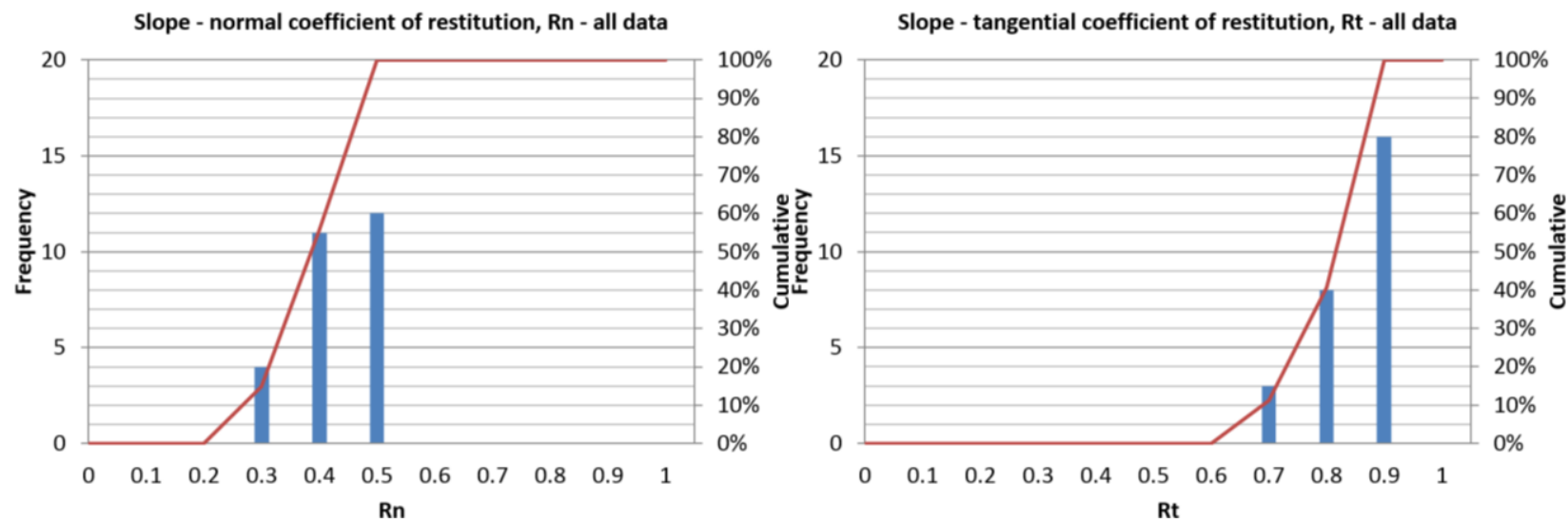

Figure 4 Histograms for bench slope coefficients of restitution from all field test data, slopes comprised clean siltstone, sandstone and quartzite faces (left: $R_{n}$; right: $R_{t}$ ) 
Table 1 presents the calibrated coefficients of restitution and adopted friction angles for 2D lumped-mass impact models.

Table $1 \quad 2 \mathrm{D}$ lumped-mass impact model — calibrated input parameters

\begin{tabular}{lccc}
\hline Ground description & $\begin{array}{c}\text { Normal coefficient of } \\
\text { restitution }-\mathbf{R}_{\mathbf{n}} \text { (mean } \\
\pm \text { standard deviation) }\end{array}$ & $\begin{array}{c}\text { Tangential coefficient } \\
\text { of restitution }-\mathbf{R}_{\mathbf{t}} \text { (mean } \\
\pm \text { standard deviation) }\end{array}$ & $\begin{array}{c}\text { Friction angle }\left(^{\circ} \text { ) }\right. \\
\text { (based on historic } \\
\text { site values) }\end{array}$ \\
\hline Bench floor (all data) & $0.300 \pm 0.058$ & $0.622 \pm 0.119$ & 25 \\
\hline Bench floor (weathered rock) & $0.240 \pm 0.055$ & $0.570 \pm 0.110$ & 25 \\
\hline Bench floor (fresh rock) & $0.314 \pm 0.050$ & $0.634 \pm 0.120$ & 25 \\
\hline Bench face (all data) & $0.404 \pm 0.061$ & $0.837 \pm 0.073$ & 25 \\
\hline Sandstone bench face & $0.379 \pm 0.061$ & $0.825 \pm 0.083$ & 25 \\
\hline Siltstone bench face & $0.440 \pm 0.055$ & $0.810 \pm 0.055$ & 26 \\
\hline
\end{tabular}

\subsection{D rigid body impact model}

Rigid body impact models use the equations of motion and kinematics to capture the essence of fall body behaviour. They assume an instantaneous period of contact, and that the contact region between the colliding bodies is very small. Rigid body impact models consider the fall body shape and size, and various movement types including fall, slide, bounce and roll (Basson 2012).

Aside from shape, mass and friction angles, only a single coefficient of restitution $\left(C_{r}\right)$ is required in 3DRB. A coefficient of restitution, $C_{r}$, of one indicates a perfectly elastic collision with no loss in velocity or energy. In contrast, a coefficient of restitution of zero implies a perfectly plastic collision in which all of the velocity along the line of impact is absorbed (Basson 2012).

Note: the coefficients of restitution in 3DRB are different from those in 2DLM and are NOT interchangeable.

As before, the coefficients of restitution were determined from back calculation of known rock paths and endpoints from the rock fall trajectory field tests. Again, harder materials such as bench faces attained higher coefficients of restitution than softer materials such as bench floors as illustrated in Figure 5 . The outlier data points in Figure 5 (right) were a result of significantly 'long' travel paths as a result of rocks rolling on relatively shallow bench face angles $\left(60^{\circ}\right)$. Table 2 presents the calibrated coefficients of restitution and adopted friction angles for 3D rigid body impact models.
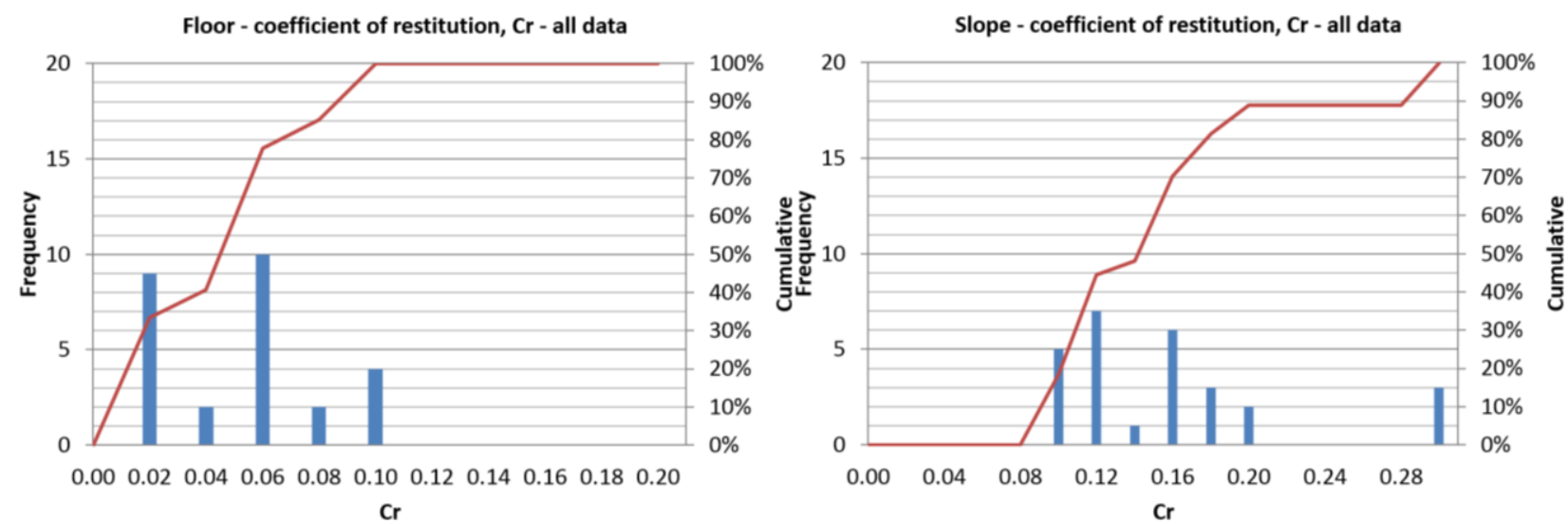

Figure 5 Histograms for coefficients of restitution $\left(C_{r}\right)$ from all field test data. Left: bench floors and haul roads. Right: bench slopes comprising clean siltstone, sandstone and quartzite faces 
Table 2 3D rigid body impact model — calibrated input parameters

\begin{tabular}{lccc}
\hline Ground description & $\begin{array}{c}\text { Coefficient of restitution }-\mathrm{C}_{\mathrm{r}} \\
\text { (mean } \pm \text { standard deviation) }\end{array}$ & $\begin{array}{l}\text { Static friction } \\
\text { angle }\left({ }^{\circ}\right)\end{array}$ & $\begin{array}{l}\text { Dynamic friction } \\
\text { angle }\left({ }^{\circ}\right)\end{array}$ \\
\hline Bench floor (all data) & $0.049 \pm 0.028$ & 65 & 60 \\
\hline Catch bench & $0.037 \pm 0.021$ & & \\
\hline Haul road & $0.074 \pm 0.021$ & 50 & 40 \\
\hline Bench face (all data) & $0.155 \pm 0.060$ & & \\
\hline Weathered bench face & $0.125 \pm 0.028$ & \\
\hline Fresh bench face & $0.164 \pm 0.065$ & & \\
\hline
\end{tabular}

\section{$4 \quad$ Assessment of standard slope geometry profiles}

Standard slope geometry profiles were used to determine likely rock fall trajectories associated with various bench design configurations, comprising:

- Bench face angles of $60,70,80$ and $85^{\circ}$ which are assumed to be perfectly smooth in 3DRB and have a slope roughness standard deviation of $2^{\circ}$ in 2DLM.

- Bench widths of $4,5,6,7,8,9,10,11,12,13,14$ and $15 \mathrm{~m}$.

For the purpose of this paper, only $36 \mathrm{~m}$ high (triple) benches are discussed. Six stacked benches provided an inter-ramp slope height of $216 \mathrm{~m}$ for the model simulations as shown in Figure 6.

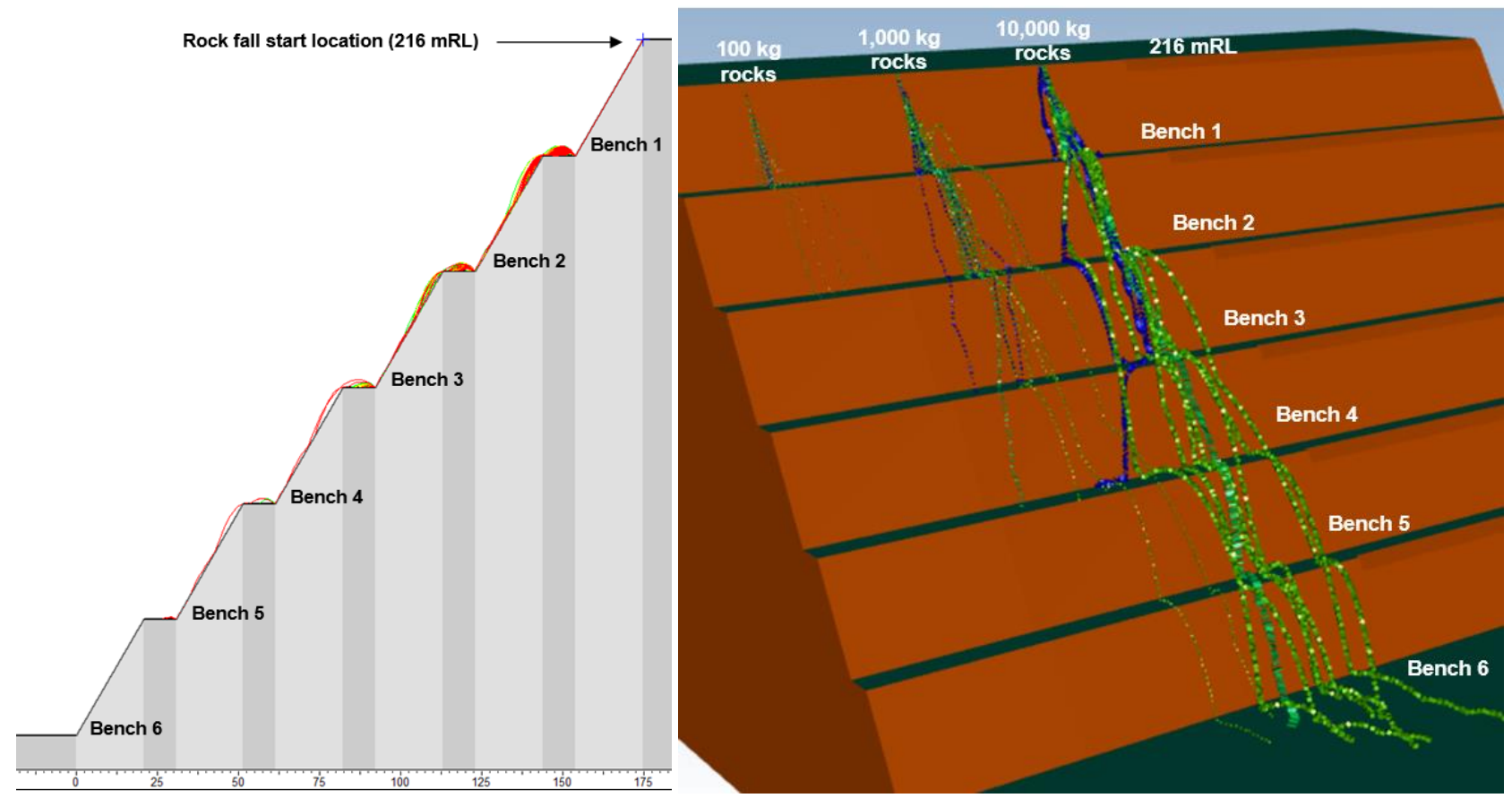

Figure 6 Bench height $=36 \mathrm{~m}$, bench face angle $=60^{\circ}$, bench width $=10 \mathrm{~m}$. Left: $2 \mathrm{DLM}$ model simulation example. Right: 3DRB model simulation example

The standard slope geometry profiles were assessed using the Modified Ritchie Criterion (presented as Equation (1); Ryan \& Pryor 2000), and 2DLM and 3DRB rock fall model simulations.

Bench width $(m)=0.2 \times$ Bench height $(m)+4.5 m$ 
To allow for variability in trajectory, several simulations tested a number of $100,1,000$ and $10,000 \mathrm{~kg}$ rocks comprising:

- Infinitesimally small spheres in 2DLM (300 test runs per configuration).

- Appropriately sized cubes, elongated flat boxes and angular 'smartie' shapes in 3DRB (90 test runs per configuration).

The percentage of rocks captured on benches using 2DLM and 3DRB model simulations are presented in Figure 7. Both models show that narrower bench widths are likely to capture fewer rocks than wider benches. The 2DLM model simulations suggest a higher 'certainty' for capturing rocks for 'wider' benches compared with the 3DRB models. This is more clearly evident in Figure 8, which compares the percentage of rocks captured on the first bench between the 2DLM and 3DRB model simulations.

In Figure 8, smooth, almost variability-free curves are obtained from 2DLM model simulations. Re-running these simulations would yield near-identical results.

Conversely, in the 3DRB model simulations, a high degree of variability can be observed in the results (i.e. non-smooth curves). Additionally, when re-running these simulations, identical results are not obtained, but vary in the order of $5-10 \%$.

Both results suggest the Modified Ritchie Criterion (Ryan \& Pryor 2000) may not be admissible for $36 \mathrm{~m}$ high benches. Note that for 12 and $24 \mathrm{~m}$ high benches, the Modified Ritchie Criterion was found to be satisfactory using 2DLM.

As illustrated by both Figures 7 and 8 , steeper bench face angles generally result in shorter rock fall trajectories.

Maximum horizontal run-out distances from individual benches were also modelled using 2DLM and 3DRB. The results are illustrated in Figure 9 for 12, 24 and $36 \mathrm{~m}$ high benches.

\section{$5 \quad$ Key findings}

Key findings from the rock fall trajectory field tests and model simulations are:

- Steep bench face angles predominantly result in a 'fall' motion and generally reduce horizontal rock fall trajectories. Conversely shallower bench face angles promote 'rolling' and 'bouncing', which increase horizontal trajectory.

- Smooth bench faces reduce the likelihood of launch features contributing to horizontal trajectories.

- Triple benches (36 $\mathrm{m}$ high) increase the velocity of rock falls and as such, the trajectories.

- Minor changes in coefficients of restitution (particularly in 2DLM) can yield significantly different results (note: this was identified during the model calibration phase). As such, models without calibration seldom add significant value to a project.

The 2DLM model simulations often exhibit 'ellipsoidal' trajectories, which were not observed in field testing. The 3DRB model simulations provided more realistic rock fall trajectories; however, trajectories were greatly influenced by the fall body shape and size. This caused significantly more variability in the modelling results than the 2DLM model simulations. Based on the writers' experience, this better reflects actual variability of rock fall trajectories that may be observed in the field.

The 3DRB model simulations are believed to add significant value as they illustrate that it is difficult to definitively model rock fall trajectory paths. However, the information is very useful in determining the likely endpoints of rock fall trajectories which can be used in design.

The rock fall trajectory field tests and model simulations assisted in the review of slope designs, risk in current operating pits, and in refining procedural controls to manage rock fall risk. 
2D lumped-mass model: bench face angle $60^{\circ}$, bench height $36 \mathrm{~m}$
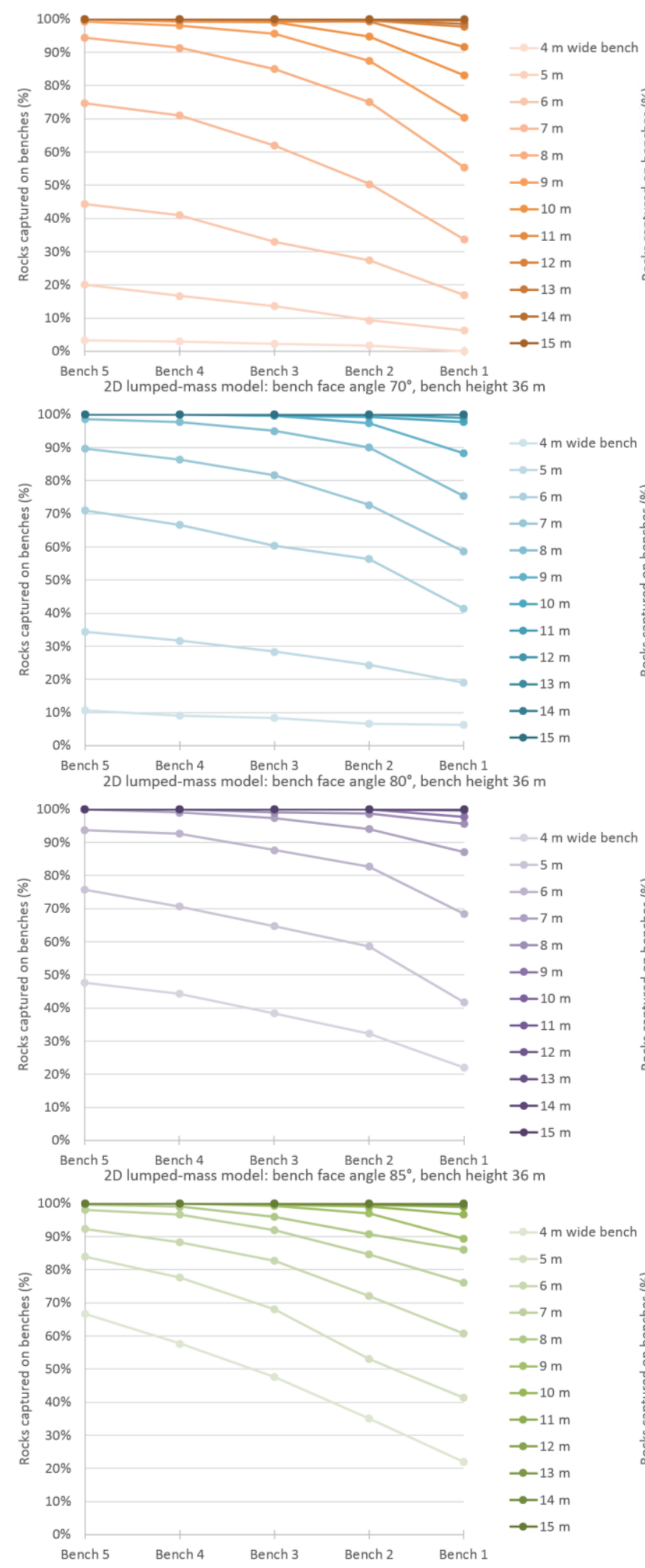

$3 \mathrm{D}$ rigid body model: bench face angle $60^{\circ}$, bench height $36 \mathrm{~m}$

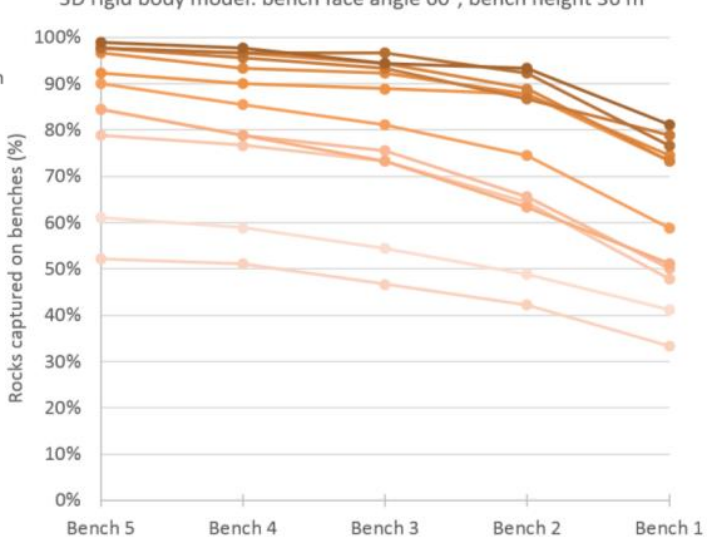

3D rigid body model: bench face angle $70^{\circ}$, bench height $36 \mathrm{~m}$
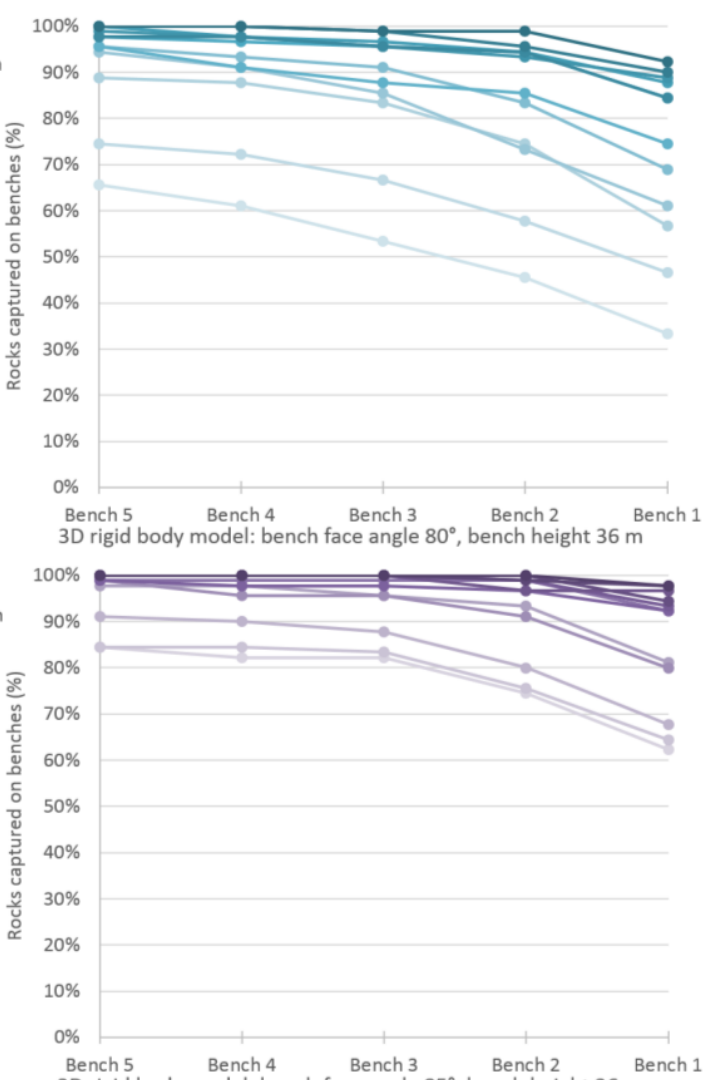

Bench 5
3D rigid body model: bench face angle $85^{\circ}$, bench height $36 \mathrm{~m}$

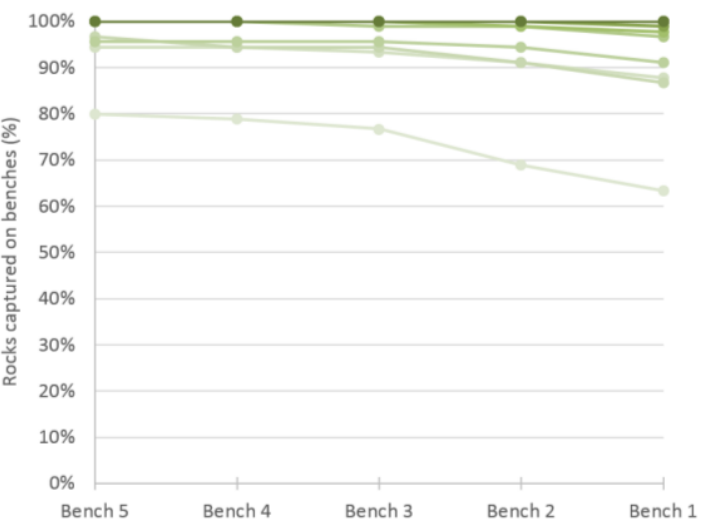

Figure 7 Model simulation results: percentage of rocks captured on benches. Left: 2DLM. Right: 3DRM 
Bench height: $36 \mathrm{~m}$

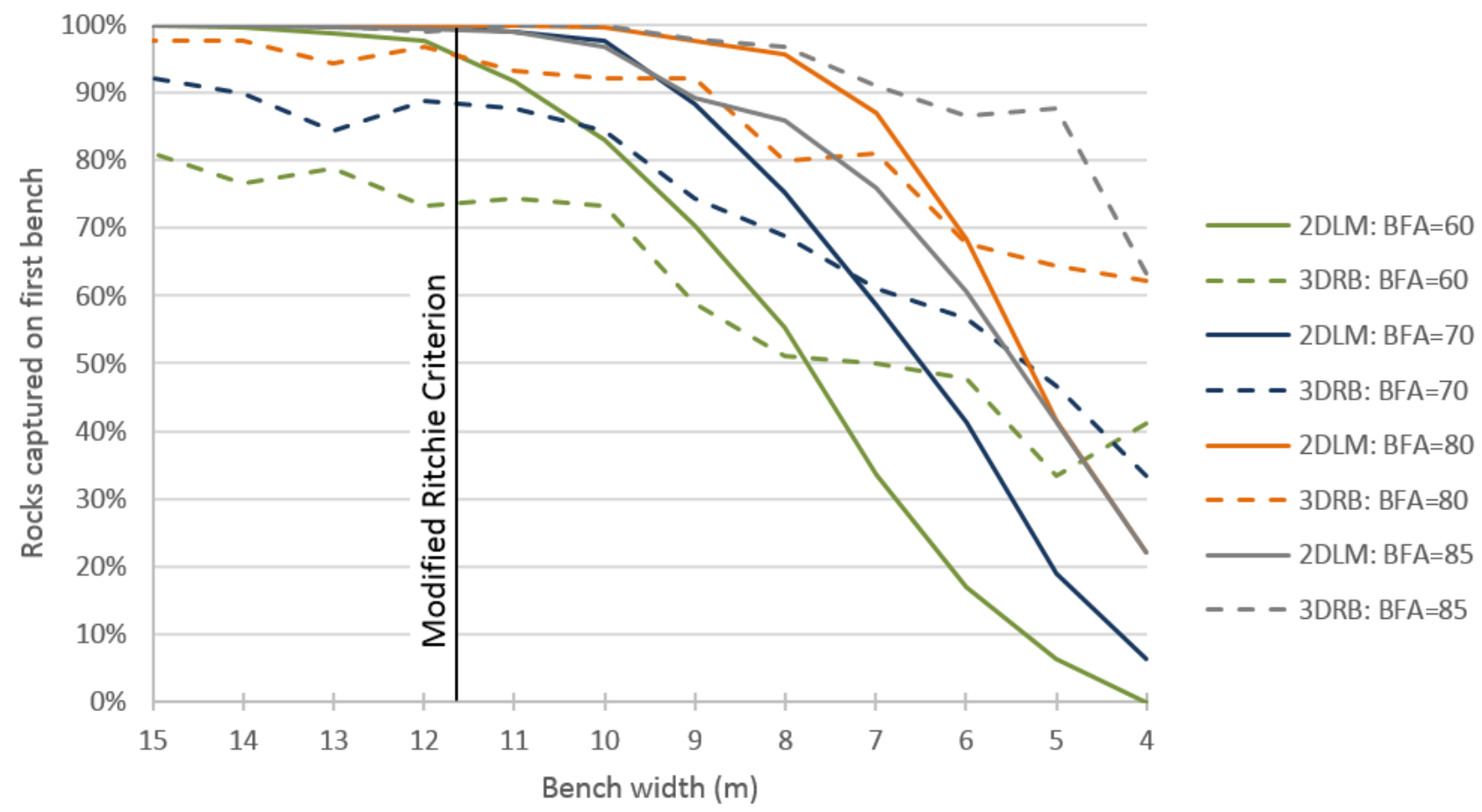

Figure 8 Percentage of rocks captured on the first bench from 2DLM and 3DRB

Individual bench maximum run-out distance - all bench configurations

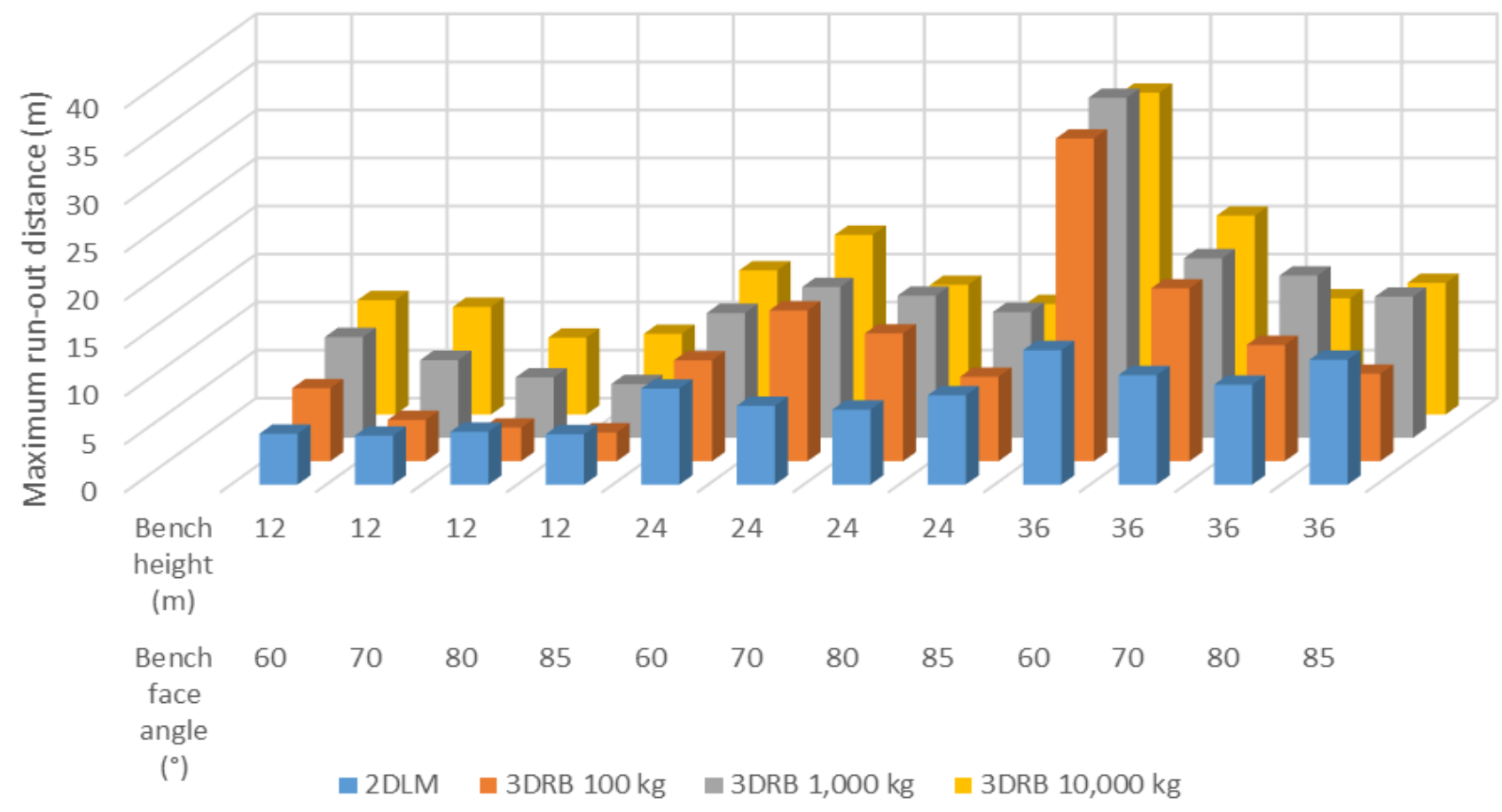

Figure 9 Individual bench maximum run-out distance from 2DLM and 3DRB 


\section{$6 \quad$ Future work}

Future planned work also includes further field testing to better understand the absorption on rock fill catchment bunds, haul roads and bench floors. Additional analysis is planned to understand the first impact point near the base of the slope and the effect of catchment bunds near the base of the slope.

\section{Acknowledgement}

The authors acknowledge the Newcrest Telfer gold mine Technical Services and Mine Production teams for facilitating equipment-assisted rock fall trajectory field testing, and Mark Reynolds for providing additional case studies.

\section{References}

Ashayer, P 2007, Application of rigid body impact mechanics and discrete element modelling to rockfall simulation, PhD thesis, University of Toronto, Canada.

Basson, FRP 2012, 'Rigid body dynamics for rock fall trajectory simulation', in Proceedings of the 46th US Rock Mechanics \& Geomechanics Symposium 24-27 June 2012, American Rock Mechanics Association, Chicago.

Basson, FRP, Humpries, R \& Temmu, A 2013, 'Coefficient of restitution for rigid body dynamics modelling from onsite experimental data', in P Dight (ed.), Proceedings of Slope Stability 2013: International Symposium on Rock Slope Stability in Open Pit Mining and Civil Engineering 25-27 September 2013, Australian Centre for Geomechanics, Perth.

Bosman, JD \& Kotze, G 2015, 'Verification of catch berm effectiveness through the application of 3D fall body dynamics', in Proceedings of Slope Stability 2015, International Symposium on Rock Slope Stability in Open Pit Mining and Civil Engineering 12-16 October 2015, Cape Town, South Africa.

Budetta, P \& Santo, A 1994, 'Morphostructural evolution and related kinematics of rockfalls in Campania (south Italy)', Engineering Geology, vol. 36, pp. 197-210.

Chau, KT, Wong, RHC \& Lee, CF 1996, 'Rockfall problems in Hong Kong and some new experimental results for coefficients of restitution', International Journal of Rock Mechanics, Mining Sciences and Geomechanics, vol. 35, pp. 662-663.

Dadashzadeh, N, Duzgun, HSB, Yesiloglu-Gultekin, N \& Bilgin, A 2014, 'Comparison of Lumped Mass and Rigid Body Rockfall Simulation Models for Mardin Castle, Turkey', in Proceedings of the 48th US Rock Mechanics \& Geomechanics Symposium 1-4 June 2014, American Rock Mechanics Association, Minneapolis.

Hoek, E 2007, Practical Rock Engineering, 2007 Edition, Vancouver, Canada, viewed 12 February 2016, https://www.rocscience.com/learning/hoek-s-corner

Ritchie, AM 1963, 'Evaluation of rock fall and its control', Highway Research Record 17, Highway Research Board, Washington, pp. 13-28.

Robotham, ME, Wang, H \& Walton, G 1995, 'Assessment of risk from rockfall from active and abandoned quarry slopes', Institution of Mining and Metallurgy Section A, vol. 10 (Jan-Apr), pp. A25-A33.

Ryan, TM \& Pryor, PR 2000, 'Designing catch benches and interramp slopes', in WA Hustrulid, MK McCarter \& DJA Van Zyl (eds), Slope Stability in Surface Mining, SME, Colorado, pp. 27-38. 